\title{
ESPIRANDO EL ITINERARIO GUIADO. Materiales para recorrer un periplo excitante en el museo
}

\author{
Ana TIRADO DE LA CHICA \\ Universidad de Jaén (España) \\ atirado@ujaen.es
}

GUIDED ITINERARY EXHALING. Materials to travel a exciting periplus at the museum.

Resumen: Con este trabajo pretendo abordar un conocimiento significativo sobre mi relación sensible y experiencial reciente en los sitios de los museos, y tratar de comprender el cambio de mirada sobre el imaginario del museo que he experimentado en mi carrera de estudios, profesional y personal, que abordo desde una metodología indagadora performativa de la experiencia museal.

Abstract: In this work, I try to address a significant knowledge about my recent sensitive and experiential relationship sites museums, and try to understand the change of view on the imaginary about museum that I have experienced in my career studies, professional and personal live, that board from a performative inquiring methodology of museum experience.

Palabras clave: Museo; Indagación; Performance; Experiencia; Goce

Museum; Inquiry; Performance; Experience; Enjoyment 


\section{Introducción}

Este trabajo parte de mi trayecto personal como estudiante e investigadora en torno a las artes, primero, y como apasionada del museo, después. Así, empezaré este trabajo poniendo de manifiesto la adoración que siento por los museos, y confesando que no concibo un calendario sin museos, y mucho menos ir a otros lugar y no hacer el intento de conocer sus museos (en ocasiones, los museos han sido el motivo principal para visitar otras ciudades). Y así, cuando el callejero de una nueva ciudad llega a mis manos, lo primero que suelo hacer es localizar sus museos, al menos los más destacados. Sin embargo, esta forma de interesarme por los museos no siempre la pensé así, incluso hubo un tiempo en que esta no existía. Recuerdo incluso un tiempo en que tras los muros de piedra que rodean el Museo de Jaén -la ciudad donde crecí y resido-, imaginaba un lugar en penumbra y sombrío, y la verja negra que resguarda la entrada a pie de calle (el Paseo de la Estación, una de las avenidas principales), me parecía como la de cualquier mansión solitaria en unos dibujos animados de terror.

Me pregunto, entonces, cómo fui construyendo este imaginario del museo como sitio de las artes y como lugar donde gozar, curiosear y "pensarse". Esta pregunta me inquieta por una doble cuestión: por un lado, en este periodo adulto y de dedicación profesional como nunca antes había vivido, asisto con frecuencia a debates que tratan asuntos muy críticos con las actividades en los museos, referidos tanto a exposiciones, políticas culturales, de gestión, programas educativos, etc., para los que razones y casos no faltan, y con los que yo misma me siento de acuerdo. Por otro lado y abordando aquella misma cuestión pero en otro sentido, sigo experimentado un gran placer en mis visitas a los espacios museales, ya sea en el mismo entorno donde resido y que tengo por cotidiano, o cuando visito otros lugares, en cuyos casos la intensidad de mis emociones es incluso mayor desde la idea misma del viaje. Ante esta doble disyuntiva que expongo, confieso que me encuentro en el intersticio de una gran paradoja sobre los museos: entre una teoría crítica (Navarro y Tsagaraki, 2010-2009; Lorente, 2006) que arremete fuertemente contra determinadas formas políticas y educativas, sobre la gestión de los museos, y una vivencia personal excitante en los lugares museales.

El primer contacto que pude tener con un museo y que recuerde fue en el Museo de Jaén en el marco de una visita escolar. Sucedió cuando me encontraba en edad de Infantil o de Primaria. Durante mucho tiempo después, en mi memoria quedó la imagen de estar tumbada en el suelo junto a mis amigos de clase y dibujar, siguiendo las indicaciones de "la seño" y otra señorita del museo, una especie de animal con melena y alas sobre un cuaderno blanco. Así, durante varios años, quedó en mi memoria la sensación desorientada de no alcanzar a delinear "correctamente" lo que tenía frente a mis ojos, al tiempo que no podía "escapar" de aquella situación. Más tarde he podido entender que me encontraba dibujando la figura de una de las esculturas de animal de la sección ibérica del Museo, y que la representación figurativa y naturalista de las cosas no era lo mío.

Años más tarde, mi relación con los museos se intensificó al cursar estudios de Historia del Arte en la universidad. Entonces se trataron de visitas guiadas por diferentes profesores, de cuyas manos visitábamos museos afines a las diferentes materias. Así visité, en Granada, el Centro José Guerrero, el Museo de Bellas Artes, el Museo de los Tiros; en Madrid, la ampliación del Museo del Prado, el Museo Nacional Centro de Arte Reina Sofía, el Museo Arqueológico Nacional, Caixa Forum, el Museo Thyssen-Bornemisza; en Sevilla, el Centro Andaluz de Arte Contemporáneo de La Cartuja; y otros tantos en Málaga, Córdoba, Almería, Toledo, etc. En estas visitas de estudios a los sitios museales, el destino era la colección de obras de arte del museo y su tratamiento museológico y museográfico en las salas de exposición. Confiada del criterio de la institución, seguía sus itinerarios a raja tabla, convencida de que serían los mejores pasos hacia un conocimiento comprensivo y correcto de las obras de arte y de la historia. Andaba por las salas del museo con libreta y bolígrafo 
en mano; rígida como una estaca, pasaba decenas de minutos frente a un cuadro principal y tomaba notas sobre aquellas referencias de otros autores o cuestiones técnicas del trazo, la línea y el color que encontrara; también portaba en algunos de los bolsillos del pantalón vaquero mi cámara de fotos, y fotografiaba aquellos atributos iconográficos que no conocía o que relacionaba con otros, para posteriormente preguntar estas curiosidades a alguno/a de mis profesores, como quien indaga sobre un acertijo.

En medio de mis estudios de Historia del Arte, mi interés por las materias de Patrimonio, Educación artística y Gestión cultural me llevó a inscribirme y participar en otros cursos especializados y que en ocasiones se impartían en otras ciudades. Pienso que fue así que comenzaron mis periplos en los museos. Durante tres días o una semana, empecé a visitar otros lugares con mayor frecuencia -y en solitario la mayor parte de las veces-. Sin una intención clara en ello, de pronto empecé a gozar simplemente mis vaivenes en los museos. A veces volvía a museos que había conocido anteriormente por las visitas con el grupo de la universidad; me vanagloriaba de reconocer las cosas por segunda vez y aprovechaba la ocasión para contemplar más detenidamente ciertas obras. En otras ocasiones, por ejemplo con el callejero de Madrid, me dirigía a centros de arte que estaban señalados en el mapa y de los que podía tener tan solo una remota idea, muy poco clara, de lo que podría encontrar allí. Así fue como conocí "a mi gran amor" de Madrid: La Casa Encendida. Fue en un verano de 2010 en que fui a la capital por una semana para asistir a un curso del Instituto Superior de Arte. Al finalizar la jornada de uno de los días, encontré en algunos de los cientos de panfletos publicitarios de la actividad cultural en Madrid que habría un concierto en la terraza de La Casa Encendida. Ya había tenido alguna referencia sobre este sitio como algo alternativo, así que me pareció un plan perfecto para una noche de verano en Madrid. Llegué a Casa Encendida con bastante antelación con la idea de conocer el centro. Y, qué maravilla... Qué fantástica sorpresa me supuso encontrar una exposición dedicada al cine punk y de grupos marginales de los años 80. La exposición contaba con materiales muy diversos y así la información la iba encontrando en diferentes formatos que debía experimentar en el momento y en el sitio: el techo y paredes de la entrada cubierta con pósteres publicitarios, un par de salas de proyección, fotografías, recortes de prensa... Cuando fue la hora, subí hasta la última planta del edificio y accedí a la terraza; en el suelo había repartidos una cantidad de cojines y tomé asiento en uno; de pronto me encontré rodeada de otra mucha gente, sentada también en cojines, y frente a una corta explanada de la terraza. La obra consistió en una pareja masculina que, empleando diferentes materiales y objetos cotidianos, trabajaban en la creación sonora a través de la performance. Me encontré en un sitio que me alucinó. De ese viaje y corta estancia en Madrid conservé con cuidado y añoranza el ticket de entrada a Casa Encendida. Y, desde entonces, en cada visita a Madrid, procuro pasarme por allí. A veces, he tenido un tiempo escaso, así que he tratado de aprovechar el momento del almuerzo a mediodía para disfrutar en el restaurante de alimentos ecológicos de Casa Encendida, y después descansar tomando café en su sofá.

Narrando estos diferentes pasajes que he vivido en los museos, voy encontrándome en el intersticio de una gran paradoja, como he anunciado inicialmente. Con ello me refiero a que, hasta ahora, por un lado, he focalizado mis investigaciones sobre las formas de gestión y de responsabilidad en torno a los programas de educación en museos, algo que con frecuencia me ha situado en discursos muy formales y que me ha conducido a un carácter rígido y seco en el tratamiento de mi investigación. Creo que, en cierto modo, he trabajado sobre una epistemología del museo que no se ha separado de la propia perspectiva de este tipo de institución, a pesar de que en el proceso de la investigación me he permito licencias científicas y propias para diseño de métodos y herramientas empleados.

En otro sentido, a lo largo de mis vivencias y largos periodos de estudio en los sitios museales que han sido objeto de estudio de mis investigaciones -residencias en el lugar-, he experimentado determinados momentos "de fuga" con respecto al objetivo principal que me 
hubiera marcado. Me refiero en este caso a aquellas ocasiones en las que, en el museo, me desvestía de la mirada de la investigadora universitaria que me había marcado y, sin una intención ni dirección precisas, me disponía a "vagabundear" -indagar, aunque al principio no lo sabía- por los espacios del museo en cuestión. Entonces desechaba cualquier plano o guía que pudiera "adivinarme" la experiencia por venir y me sumergía en el buceo de un periplo propio de emociones, encuentros y excitaciones en el museo. Mi rol de participación con respecto al museo no se encuentra vinculado a los servicios del museo de una manera implícita y considero que esta condición personal resulta fundamental en mis formas de relación con los museos y en el imaginario de museo que he ido construyendo. Así, mi actividad profesional, que es de tipo investigadora, la desempeño desde el marco científico de la Universidad. Si bien tengo por objeto de estudio los aspectos educativos y de responsabilidad social del museo, este no lo abordo en primera persona desde el departamento educativo de un museo ni desde el servicio del museo, sino desde una posición participante, pero también con la distancia que te da el que no tenga que responder a los criterios y objetivos definidos propiamente por la política del museo.

Si anteriormente aludía a una teoría crítica referida al museo, quisiera anotar que esta soporta en su base una discusión de corte economicista, dado que sus argumentos se refieren a cuestiones de la funcionalidad y de la rentabilidad, tanto del museo como de sus servicios (de publicaciones, de comisariado, de educación, de atención al público, de merchandaising...). Siguiendo a Díaz de Rada (2008), el valor de las cosas se considera en relación al rol del sujeto, del uso que del objeto en sí haga y del contexto de referencia en que se encuentre. Mi relación con el museo como objeto de estudio en mis investigaciones consiste en adentrarme entre sus aristas de intereses y objetivos, y dirigirme hacia el conocimiento de estas situaciones y de su comprensión significativa. Como respuesta, me sitúo en un rol de crítica y de reclamo de las formas museales hacia aquellas que encuentro que ofrecen mayores posibilidades sociales y comunitarias con las sociedades actuales. Junto a estas, gozar el sitio del museo se ha convertido en uno de mis valores primordiales, y es esto precisamente lo que persigo experimentar y vivir a lo largo de mis periplos por los museos.

\section{El goce estético, lo sublime y otras excitaciones en el museo}

Platón (427-347 a.n.e.), Santa Teresa de Jesús (1515-1582), Burke (1729-1797), Lyotard (1924-1998), etc., todo ellos escriben sobre lo bello, lo divino o lo sublime para referirse a estados de carácter sensible que podemos experimentar una cierta superación de la realidad misma y, de algún modo, sentirnos extasiados por esa emoción o idea. De este modo, en las esculturas clásicas de la Antigua Grecia y Roma encontramos esculpida, sobre una dureza primera de los materiales de mármol y piedra que empleaban, una especie de contención sensual de la realidad de los movimientos cúlmenes de una acción que nos evoca más allá de la acción real misma, e imaginamos o soñamos o sentimos (o todo a la vez) la excitación de una máxima humana y vital (Peñuela, 2007). Santa Teresa también dio testimonio de sus meditaciones en el plano religioso y de lo divino. Narraba en torno a sus experiencias entre el rezo y la reflexión como si surcase trayectos de elevación del alma (Otger y Dios, 1997). Burke a finales del siglo XVIII se refiere directamente a las pinturas como evocadoras de la imaginación, la fantasía y el terror. Así, habla de las sombras y el tratamiento oscurecido del color como culpable y motivador de todo ello. De las reflexiones y críticas de este periodo se fue dando lugar al estilo romántico tanto de la pintura como de la literatura, etc., empeñado por tintes de las ruinas góticas y de la decadencia. Un paisaje de ruinas integrado entre las hierbas de la pradera y del bosque inglés en Europa, con respecto a los cuales la condición humana pensaba abrumarse o alzarse sobre la inmensidad (Burke, 2010). En el contexto en que Lyotard plantea su reflexión en torno a lo sublime o a las situaciones de superación de la cuestión estética, ya se habían superado las pugnas entre artista, mecenas y 
condición creativa por lo que tanto apostaron las vanguardias artísticas. Cuando Kandinsky fue explorando cada vez más el campo de la abstracción en el arte, lejos quedaba ya de un trabajo sensible, divino o manual. Así, las vanguardias artísticas superaron la condición de representación del arte por una condición de creación y conocimiento propios, que Lyotard planteó en clave de "presentación» del arte. En este sentido, para Lyotard la emoción de lo bello en el arte quedaba sujeta a cuestiones estéticas de la representación y que eran más propias de las formas artísticas del pasado y más tradicionales. A mediados del siglo XX, una indefinida Postmodernidad había superado los cánones de pretensiones universalistas para el arte. Por tanto, Lyotard plantea una noción de lo sublime por oposición a lo bello. Si en una esfera de la representatividad del arte se alcanza por la visualización de lo bello, en esta ocasión y en una esfera de la presentación del arte, se llega a una experiencia sublime dejándose embaucar por el intersticio sutil y poético de lo que se interpreta o se entiende de una obra, pero que no está dicho, que no es visible. Esa delicada laguna del pensamiento y de la emoción -ambas por igual- nos sitúa como sujetos en un momento mágico de imaginación y poesía, que nos evoca a una emoción o situación sensible sublimes. Esta idea de lo sublime no está por tanto sujeta a una fuerte expresividad, ya sea heroica, vulgar, paradisíaca, etc., sino a una comprensión sensible e intelectual del objeto o suceso artístico que, primero al autor y después también al receptor, nos sitúa interpela y debate sobre nuestra propia condición humana del presente (Ramírez, 2010).

\section{Una metodología indagadora en el espacio museal}

La metodología de esta investigación la abordo como una indagación performativa en el sitio del museo. De este modo, yo misma como investigadora me sitúo en el papel de sujeto de estudio de la investigación para pensarme para con los otros y con el medio en el que me relaciono. Apelo de este modo no a una lógica racional de los hechos sino a mi condición sensible como sujeto cognoscente que me mantendrá focalizada en mis percepciones y estados en el sitio.:

"puede ser la oportunidad para aprender desde el cruce entre pensar, conocer, actuar e interpretar lo que hemos decidido observar o lo que al principio permanece invisible" (Hernández, Forés, Sancho, et al., 2011: 12).

En la indagación, la investigadora constituye el sujeto de estudio, y me sitúo en el lugar o lugares donde acontece el objeto, no para documentar explícitamente lo que se observa, sino para explorar las percepciones de las situaciones. Por tanto, la investigación parte de un plan inicial, pero este queda abierto y dispuesto a incorporar los imprevistos y otros elementos que fueran apareciéndose y encontrándose en el transcurso del proceso de la indagación (Hernández, Forés, Sancho, et al., 2011). Así, me sitúo en el transcurso de procesos dialógicos entre el contexto sociocultural del museo y, yo misma, en los que las cuestiones de discusión de amplían y diversifican, al tiempo que se expanden los elementos del sitio a explorar. Me dispongo, no a una recolección de datos aún de carácter cualitativo, sino a realizar una inmersión experiencial y reflexiva de lo que me acontece en el lugar del objeto de estudio que los constituye el museo. Abordo la investigación como un proceso creativo a lo largo del lugar voy estableciendo vinculaciones significativas en torno a las cuestiones que voy encontrando, y que pueden ser de diferente naturaleza: materiales, inmateriales, emocionales, físicos, ambientales, etc. En la indagación performativa la investigadora no se limita a emplear su trascurso por el sitio para una explícita recolección de datos según los ítems predefinidos para la investigación. Supone, sobre todo, que la investigadora se sitúa en una condición favorable para repensarse su apercepción del espacio y de lo que allí entiende que le acontece (Hernández, Gómez, y Pérez, 2006). 
En las motivaciones y objetivos para realizar este trabajo, quiero tratar el cambio de mirada que he experimentado sobre el museo y el cambio en las formas de relacionarme con estos espacios del arte. Forzosamente, este cambio intersubjetivo sobre el imaginario del museo debe vivenciarse en clave de primera persona en el seno d una inmersión prolongada y experimental dentro mismo del sitio. Mi rol con respecto al sitio del museo es completamente activo, en el sentido de que participo de las propuestas de actividad y acción de sus espacios y dispositivos. También con respecto al grupo social que es propio del museo, el personal de la institución, mi rol es activo. Participo de las dinámicas propias y que podría esperarse de un visitante o persona del público (Guber, 2001).

Para la recogida de datos en este tipo de trabajo, resulta de gran importancia que la investigadora desarrolle la experiencia en el sitio del museo con el menor riesgo de distracciones e interrupciones externas a la experiencia misma. En este sentido, las anotaciones en un diario de campo, que sería propio de cualquier estudio en primera persona en el sitio, lo he rechazado, y empleo únicamente una cámara de fotografías y de vídeo para documentar aquellos sitios y ocasiones que como investigadora viva con mayor interés e intensidad. Así, los documentos recogidos que puedan testimoniar el trabajo deben acercarse lo más fidedigno posible a la experiencia vivida por la investigadora, esto es, en el plano visual, sonoro y corporal, al menos. Por otro lado, el ejercicio de la documentación que emplearé no será un objetivo en sí más para recolectar datos que posteriormente puedan refutar o mostrar una idea, sino que debe entenderse como la respuesta a un impulso emotivo que la investigadora siente para conservar consigo misma, no como un archivo de documentación, sino como un tatuaje de rituales. Para intensificar la experiencia de lo vivido, se desaconseja una intensa documentación previa sobre el museo, dado que significará adquirir ideas preconcebidas sobre la visita y se genera así una idea de prejuicio sobre el museo. Este ejercicio de documentación con fuentes secundarias sobre el museo podrá realizarse a posteriori de la visita, para justificar o profundizar determinados aspectos. Recordaré que, según ya se planteaba en la introducción de este trabajo, he desembocado en gran parte de estas situaciones y experiencias, no tanto por conocer un museo ya esperado, sino por curiosear sitios desconocidos que aparecían señalados en los mapas y callejeros de las ciudades que iba visitando.

\section{Pérdidas y encuentros en el museo}

Orientación y desorientación me suceden en los sitios de los museos a la par. No tanto una por oposición a la otra, sino que más bien encuentro que ambos se alternan en mis experiencias permanentemente. De hecho considero que mi errancia en los museos consiste en una sucesión constante entre destellos de orientaciones y destellos de desorientaciones. En un vaivén de encuentros y desencuentros llego y salgo del museo. Fue la ocasión por ejemplo de encontrarme con el Musée de l'Architecture et du Patrimoine (París) que se emplaza en la zona de Trocadéro. Esta era mi única referencia sobre la localización del sitio, por lo que llegué hasta ese destino premeditado según las indicaciones y señales en los mapas de metro de la ciudad. Aún en el subsuelo buscaba la salida de metro con dirección a Place du Trocadéro, no como quien vislumbra el final de un trayecto sino la continuación de un paso más. Conseguí dar con las escaleras que parecían más oportunas, y llegué a una enorme explanada dominada en su centro por una gran rotonda de tráfico. A mis espaldas, edificios de vivienda con bajos comerciales atiborrados de mesitas de terraza. Y, frente a mí, continuaba un prominente horizonte protagonizado por la flamante Torre Eiffel de París. A ambos lados de esta visualizaba dos edificios simétricos de gran magnitud construidos en piedra, con un marcado carácter imperialista pues en cuyas fachadas se alzan sendos pilares. Durante unos minutos no reparé demasiado en ellos, pues había quedado seducida por este paisaje nublado de París. Desde esa experiencia en esta salida de metro de París, supe que había encontrado uno de los más bellos regalos que haría de ahí en adelante a los amigos 
y familiares de fuera que me visitaran: esta vista sorpresa en París. Retomando de nuevo el rumbo hacia el Musée de l'Architecture et du Patrimoine, intuí que se trataría de esos edificios colosales. De entre los dos que divisaba, inicié el camino hacia el que tenía más próximo. En el trayecto, debí hacer dos momentos de pausa en pasos de cebras, en cuyas paradas volví a desorientarme con respecto al museo, alzando la mirada hacia la extensísima explanada hacia la Torre Eiffel. En el primero de los edificios al que accedí, no se encontraba el museo, sino que los carteles y pósteres de difusión se referían a un teatro. A pie de calle, el otro edificio gemelo quedaba a una distancia considerable de varios metros. Para llegar hasta allí, debía caminar cruzando la gran explanada y mirador frente a la Torre Eiffel. Parar el paso de nuevo y querer empatizar con esa mirada del imaginario parisino supuso un imán físico y emocional. Al poco volví a retomar el paso, alcancé el otro lado, me alcé sobre cada uno de los peldaños de piedra clara delante de la fachada, y atravesé la primera de las puertas de entrada con marco de hierro en negro y decorados en dorado. Llegué a un segundo acceso restringido a un solo pasillo donde se encontraba un control de seguridad a quien debí mostrar el interior de mi mochila. Y ya en el interior del edificio, en el recibidor de la entrada, cuando parecería que todos los muros internos del edificio convergerían hacia los contenidos particulares e identitarios del museo, diviso al fondo de la sala unos altísimos ventanales que dejan contemplar el paisaje parisino de la Torre Eiffel en el exterior. En tal situación, una vez más me olvidé del mostrador de venta de tickets, a mi izquierda, me olvidé del ropero y de la tienda-librería, a mi derecha, y me dirigí hacia aquel ventanal del fondo como asumtada por la emoción poética del momento.

\section{El encuentro en una dimensión personal propia}

Me encontré a mí misma en el MAC/VAL, y debo contarlo así para ser honesta y sincera con mis pensamientos y emociones. No quiero referirme con ello a quien se define o etiqueta, sino muy al contrario, como quien se descubre hondamente en una gran condición incierta y múltiple, como quien se sabe propia en un sinfín de posibilidades. Sucedió en el periplo de visitar y transitar los espacios y contenidos de este sitio, donde sentí el abrazo del museo. No del consuelo ni de la empatía, y mucho menos de la felicitación. Se trató del abrazo de quien como tú se cuestiona en su presente y en el contexto que nos tocó, y sabe que los intentos de respuesta son propios al tiempo que se van tejiendo en diálogo juntos. Entonces los dos abrimos los brazos, nos soltamos y nos dejamos caminar, sin prisa, sin vigilancia, y permitiéndonos todos los movimientos, trayectos y vueltas que imagináramos. Dejándome confiar, no en la autoridad vigía, sino en quien tiene cosas que contar.

Las referencias de este sitio me llegaron por recomendación de otro profesional en materia de museos, quien me aconsejó visitarlo para conocer una propuesta reciente de museo en cuyos propósitos de base rige una importante apuesta por el trabajo comunitario y local desde el museo. Primero visité su web donde encontré un discurso que promovía la participación activa de los públicos y de la comunidad. Así, por ejemplo, encontré la publicidad de talleres de danza contemporánea que se anunciaban con imágenes de grupos de personas en los mismos espacios de exposición del museo. Pensé que efectivamente los equipos de este museo respondían a un uso multidisciplinar y abierto del sitio. Un día me dispuse a vivir este sitio yo misma también, y fui a visitarlo. Para una extranjera que reside por primera en París resultó un poco dificultoso y laborioso encontrarlo. La línea de bus es el medio más fácil para llegar, ya que la línea es directa y existe una parada con el nombre del museo y se encuentra por tanto muy bien señalizada. Pero esto lo aprendí más tarde. La primera vez que visité el sitio me trasladé en metro; debí realizar varios trasbordos y finalmente terminar el trayecto a pie; inicialmente desemboqué a la salida del metro en una zona de polígono y talleres de automóviles, que me desconcertó bastante para la zona residencial y urbana que había pronosticado. En la continuación de la ruta, alcancé un primer barrio de viviendas 
unifamiliares que, si bien daban un aspecto muy acogedor, prestaba continuamente atención en memorizar el recorrido por si debían retroceder en algún punto. Finalmente desemboqué en un cruce de avenidas en una de cuyas intersecciones identifiqué la sede del MAC/ VAL. Desde que accedí en la sede del museo, me encontré en una atmósfera envolvente, en una estructura que se alzaba sobre mí y me rodeaba a una escala mayor pero proporcional, donde mis movimientos podrían encontrar su sitio. En dirección a la entrada a la exposición permanente del museo, me coloco delante de un gran espacio diáfano, interrumpido por algunas columnas lisas salteadas. El piso al principio está ligeramente inclinado, y así siento que desciendo. Debo cruzarlo, pasar entre las columnas, hasta alcanzar el acceso a la exposición. Justo al lado impreso sobre el muro puede leerse:

"Vivement demain

collection du musée

Échafauder des hypothèses, tirer des plans sur la comète, construire des châteaux en Espagne, se projeter dans le futur, penser à demain, espérer...

Voilà qui est l'inévitable nature de l'homme, tel est son destin; vivre dans le présent, parfois ne pas s'en satisfaire et espérer mieux.

C'est cette projection vers de plus beaux lendemains que racontent les œuvres aujourd'hui montrées dans ce cinquième parcours dans la collection départementale, des œuvres rassemblées de façon thématique, pour mieux résonner avec le présent.

Aujourd'hui, il est donc question de demain, et de ce pouvoir d'anticipation qui est le propre de l'homme. N'est-il pas aussi ce pouvoir visionnaire que nous attribuons souvent aux artistes? Ceux-ci appartiennent-ils à cette race à part des pythies, voyants et autres prophètes?

L'artiste, en interprétant ou décryptant le monde sur des modes poétiques, personnels et métaphoriques, porte-il en lui la prémonition des temps à venir? Sa clairvoyance fait-elle de lui le messie de nos sociétés?

Sans pouvoir ni vouloir apporter de réponse, nous posons ici la question, à laquelle seul le temps à venir pourra répondre. Au fil de ce parcours et des œuvres, se déplie ici l'éventail des espoirs et des possibilités, des outils qui nous appartiennent pour faire, refaire ou transformer le monde.» ${ }^{1}$

Me detuve unos segundos... Nunca antes en un sitio del arte había experimentado la

1 Traducción de la autora al español del original en francés:

Ojalá mañana

Colección del museo

Especular hipótesis, hacer castillos en el aire, construir castillos en España, proyectarse en el futuro, pensar en mañana, esperar...

Esta es la inevitable naturaleza del hombre, tal es su destino; vivir en el presente, a veces no satisfacerse y esperar otro mejor.

Es esta proyección hacia los más bellos futuros que contarán las obras hoy mostradas en este quinto recorrido de la colección departamental, las obras reunidas de forma temática, para mejor resonar con el presente.

Hoy es entonces pregunta de mañana, y de este porvenir de anticipación que es el propio del hombre. ¿No es acaso este poder visionario que atribuimos con frecuencia a los artistas? ¿Aquellos que pertenecen a esta raza aparte de pitonisas, videntes y otros profetas?

El artista, interpretando o describiendo el mundo sobre modos poéticos, personales y metafóricos, ¿lleva en él la premonición de los tiempos por llegar?

¿Su clarividencia hace de él el mesías de nuestras sociedades? Sin poder ni querer dar respuesta, dejamos aquí la pregunta, a la que solo el tiempo por venir podrá responder. Al hilo de este recorrido y de las obras, se despliega aquí el abanico de esporas y de posibilidades, de herramientas que nos pertenecen para hacer, rehacer o transformar el mundo. 
duda planteada por el mismo museo. Me dispuse así en una actitud complaciente y relajada. Volví a leer el texto, esta vez en actitud reafirmante de sus significados. Una vez vivida la emoción, sentí el impulso de fotografiar ese texto a las puertas de un museo.

En ese estado, accedí a una primera sala cuadrangular con solo tres muros, dos a ambos lados de mí y otro al fondo donde se proyectaba una obra audiovisual. El suelo estaba acolchado, y decidí soltar el bulto que llevaba y tumbarme boca abajo, apoyando los codos en el suelo para sostener mi cabeza, y gozar de mi tiempo y de la obra. Continué por una sección de fotografías a color de gran formato que pendían sobre los muros. Sobre estas interpreté temáticas muy variadas y vigentes en las informaciones de los medios de comunicación en las sociedades occidentales actuales: inmigración, estéticas culturales bellas al tiempo que opresoras con la condición de las mujeres, la deshumanización de una cultura capitalista de los valores, el retrato humano de situaciones de marginalidad y violencia juvenil, etc. De estas pasé a relacionarme con dos esculturas que se encontraban un poco distanciadas, pero con las que podría conectar visualmente. Vinculadas, pero no unidas, cada una contenía las palabras "nation" y "luxe". Fue la ocasión de rodearlas, aproximarme, alejarme... Inmersa en este complejo de traslaciones, giros, etc., pensaba no ya solo en los significados de esas palabras, sino también en cierta tirantez rígida y fría que experimentaba con esas formas lingüísticas de reminiscencias anglosajonas, cuando yo me encontraba en un entorno cultural francés y yo misma procedía de otro distinto, un contexto español de Jaén (Andalucía).

Iba explorando, observando y cuestionando las varias decenas de obras expuestas. De formatos muy diversos: fotografías, pinturas y composiciones digitales impresas en soportes bidimensionales que penden de los muros; objetos escultóricos en espacios abiertos; instalaciones visuales en espacios esquinados o rodeados por muros al menos en dos de sus lados; instalaciones sonoras en espacios cuadrangulares cerrados; proyección audiovisual sobre un muro, visualización de audiovisual en una pantalla digital; intervenciones plásticas de materiales mixtos sobre el muro, etc., etc. No entiendo que fuera recorriendo los objetos en el sentido de pasar por delante de cada uno de ellos. La disposición de los diferentes elementos refería a un cierto orden, pero este no estaba rígidamente lineado en una estructura cuyo recorrido fuera lineal. Existía un punto de entrada y otro de salida. Sin embargo, el tránsito entre las obras lo indagaba dirigiendo mi atención hacia los puntos o aspectos diversos que se exponían, y que podían coincidir con el grosso de una obra expuesta o tan solo con alguno de sus aspectos más concretos. A veces divisaba algún objeto, pero este no llamaba mi atención, y entonces me dirigía hacia otra parte. Conforme continuaba mi periplo en el museo, las diversidades tipológicas, temáticas y materiales se ampliaban. Parecía supone un nuevo encuentro, una nueva conversación. Me situaba en un perpetuo comienzo de diálogos. De una obra a otra, de un encuentro a otro, la única conexión o continuación posible era yo misma, mi cadena o red de pensamientos. Indagar en el MAC/VAL estaba suponiendo batirse y batirse una y otra vez. Pensamientos, creencias, prejuicios, recuerdos, deseos, ilusiones, añoranzas, miedos... Todo ello venía a un primer plano en mi periplo en el MAC/VAL. Me dispuse en un estado emotivo y sensible con respecto a toda la reflexión que al tiempo podía estar realizando, como un permanente goce del pensarse y del concienciarse, sin dirigirse a un destino claro. Fue en este museo de talla mediana al sur de París y ya en el distrito de Val-de Marne donde vivencié en una misma secuencia experiencial de tiempo y espacio -que podría considerar- una serie de deconstrucciones-construcciones. Lo viví como un momento, una jornada en el museo mágica y propia, que me acompañará por siempre.

\section{Conclusiones}

¿Qué ha significado en mi imaginario del museo pasar de recorrer puntos fijos de obras expuestas (como destinos pre-configurados antes de mí misma), libreta y bolígrafo en 
mano, anotando nombres de artista, a caminar por el espacio museal sin rumbo sabido, y finalmente salir del sitio sin una nota escrita y, tal vez, con esfuerzo, el recuerdo vago de algún nombre de autor/a, pero relamiéndome aún con la mirada perdida de un gran banquete de emociones? Han cambiado los continentes y contenidos que considero como predilectos de mis intereses y gustos pero, sobre todo, ha cambiado mi forma de relacionarme con el museo, lo que entiendo que significa, a su vez, que soy yo mismo que también he cambiado como público del museo. Encuentro que me siento más fácilmente acogida por aquellos sitios confeccionados a mi escala humana y que se alejan del carácter monumental y majestuoso de los grandes templos consagrados al pasado y a un tipo de saber.

En cuanto a los contenidos, me resulta profundamente interesante y curioso encontrarme con "el verde" de Velázquez en sus trabajos de pintura y su tratamiento pictórico del espacio (especialmente en "Las Meninas"); pero, en otro sentido, no es comparable a la complejidad del significado de democracia y diversidad cultural que encontré en una escultura en el MAC/VAL en forma de balanza y de pesos de diferentes tamaños y colores. En mi experiencia estética con esta segunda escultura conecté también con mi preocupación e interés por el sentido democrático en el que me debate, tanto en una escala local como global.

Así, encuentro, que para mí el museo no es destino exclusivo para una exposición de un autor más o menos de moda, o más o menos actual, sino que es destino para muchas cosas: de documentación (biblioteca, librería), de regalo (tienda de recuerdos y objetos artísticos), de actualidad, de aproximación a un grupo cultural distinto, de ocio (fin de semana), de almuerzo (restaurante) y, también y cada vez con más frecuencia, empleo el museo como lugar de descanso, ya sea en solitario o en grupo.

El museo me seduce desde su emplazamiento mismo en un determinado contexto urbano, continúa en la entrada mismo al sitio donde se me recibe con una gran honda amplitud, y se va intensificando en los recorridos por sus interiores, que como vemos no son solo de exposición. Desde que existe la idea misma de ir hasta el museo y llegar a él, ya voy participando de todo un aparataje de servicios y dispositivos. Los casos más destacados que mencionaba anteriormente, se localizan en avenidas o plazas principales donde los espacios colindantes son de gran amplitud, ya sea en forma de avenida o plaza. Y, en la medida de lo posible, el museo va a integrarse, participar y aprovechar al máximo de todas las estrategias de presentación que le ofrezca el lugar en el que se localiza. Es así como entiendo el gran aprovechamiento del emplazamiento de la Torre Eiffel se realiza con respecto al Musée de l'Architecture et du Patrimoine en París. Este museo no sólo se sitúa en el entorno próximo de la Torre Eiffel, uno de los monumentos más visitados en todo el mundo y, por extensión, funciona como un lugar estratégico de atracción de mayor cantidad de público, sino que en el diseño de su propia estructura y organización de los espacios, se disponen en su interior altísimos ventanales en los lados que dejan visibilidad hacia la Torre Eiffel desde las salas internas del Museo. Mis experiencias y tránsitos por una buena cantidad de museos me enseña que los criterios empleados para estas estructuras son muy diversos, como múltiples son las formas museales (museológicas y museográficas) que he ido encontrando. Grandes y pequeños, entre todos los museos se suceden un sinfín de categorías según los caracteres específicos de sus contenidos, intenciones aplicadas sobre ellos y formas de gestión que, como el iceberg, visualmente se manifiestan en el diseño y levantamiento de estructuras con apariencias muy diversas, que en gran parte responderán a las necesidades de sus propias bases de pensamiento y de organización. De la colección del museo y de una gran exposición temporal, a un concierto, talleres, tienda, restaurante, biblioteca, sala de lectura, cine, etc. 


\section{Bibliografía}

DÍAZ DE RADA BRUN, Ángel

2008 "Valer y valor: Una exhumación de la teoría del valor para reflexionar sobre la desigualdad y la diferencia en la relación con la escuela", en Isabel, J. R., María, y Adela, F. M. (Eds.). ¿Es la escuela el problema?: perspectivas socio-antropológicas de etnografía y educación, 345-379. Madrid: Trotta.

BURKE, Edmund

2010 Indagación filosófica sobre el origen de nuestras ideas acerca de lo sublime y de lo bello. (M. Gras Balanguer, Trans.) ( $1^{\text {a }}$ ed., $1^{\text {a }}$ reimpr.). Madrid: Alianza Editorial.

ELIAS, Amy J.

2001 Sublime Desire: History and Post-1960s Fiction. Baltimore, MD: Johns Hopkins University Press.

GERGEN, Kenneth

2007 Constructivismo social: aportes para el debate y la práctica. (A. M. Estrada Mesa \& S. Diazgranados Ferráns, Eds.). Bogota': Universidad de los Andes, Facultad de Ciencias Sociales.

GUBER, Rosana

2001 La etnografía: método, campo y reflexividad ( $1^{\mathrm{a}}$ ed.). Bogotá: Norma.

HERNÁNDEZ, F., FORÉS, A., SANCHO, J. M., SÁNCHEZ, J.-A., CASABLANCAS, S., CREUS, A., PADRÓ, C.

2011 Aprender desde la indagación en la universidad ( $1^{\mathrm{a}}$ ed.). Barcelona: Institut de Ciències de l'Educació, Universitat de Barcelona y Octaedro.

HERNÁNDEZ, F., GÓMEZ, M., \& PÉREZ, H. J.

2006 Bases para un debate sobre investigación artística. Madrid: Secretaría General Técnica, Ministerio de Educación y Ciencia.

LORENTE LORENTE, J. P.

2006 "Nuevas tendencias ten teoría museológica: a vueltas con la museología crítica", en $M u$ seos.es: Revista de la Subdirección General de Museos Estatales. Vol. 2: 24-33.

LYOTARD, J.-F.

1998 La condición postmoderna: informe sobre el saber (6 ${ }^{\mathrm{a}}$ ed.). Madrid: Cátedra.

MANSILLA, H. C. F.

2006 "La estética de lo bello y la exaltación de la cultura popular". Cuyo. Vol. 23. Disponible en: http://site.ebrary.com/lib/alltitles/docDetail.action?docID=10638439

NAVARRO, O. y TSAGARAKI, C.

2010 "Museos en la crisis: una visión desde la museología crítica», en Museos.es: Revista de la Subdirección General de Museos Estatales.Vol. 5-6: 50-57.

OTGER, S., y DIOS, E. (Eds.)

1997 Obras completas de Santa Teresa de Jesús. (9ºd.). Madrid: Autores Cristianos.

PEÑUELA, $\mathrm{J}$.

2007 "Pensar en Platón: la problemática de lo bello contemporáneo", en Calle 14: Revista de Investigación En El Campo Del Arte, 1: 111-126.

RAMÍREZ, L. O. E.

2010 "La posmodernidad, lo sublime y un ojo cortado. Nota a propósito de la estética de Jean-François Lyotard». Poliantea, 6 (11), 9.

\section{$\operatorname{cocos}$}

